\title{
CARVAJAL SYNDROME: A RARE CARDIOCUTANEOUS SYNDROME
}

\author{
A. Venkata Krishna1, Aruna Samarth², G. Manmohan³, Aradya B ${ }^{4}$
}

\section{HOW TO CITE THIS ARTICLE:}

A. Venkata Krishna, Aruna Samarth, G. Manmohan, Aradya B. "Carvajal Syndrome: A Rare Cardiocutaneous Syndrome". Journal of Evolution of Medical and Dental Sciences 2015; Vol. 4, Issue 67, August 20;

Page: 11776-11779, DOI: $10.14260 /$ jemds/2015/1698

ABSTRACT: A 3 year old girl was brought by her parents to the DVL OP. Osmania general hospital with the complaints of painful fissures and diffuse thickening of palms and soles since 10 months of her age. She was normal at birth except for presence of woolly hair, thickening of palms and soles started at 10 months of age, which was progressive and lead to formation of fissures. She was put on symptomatic treatment. Carvajal syndrome is very rare disease, so early diagnosis is important to avoid cardiac complications. (Summary)

KEYWORDS: Wooly hair, Palmoplantar keratoderma, Cardiocutaneous syndromes.

INTRODUCTION: Carvajal syndrome also known as 'Striate palmoplantar keratoderma with woolly hair and cardiomyopathy is a cardiocutaneous condition inherited in an autosomal recessive pattern due to a defect in desmoplakin gene. The skin disease presents as a focal non transgradiens striate palmoplantar keratoderma particularly at sites of pressure. The patient is at risk of sudden cardiac death due to dilated cardiomyopathy associated with this entity. It has been described in families from India and Ecuador with rare incidence.(1)

CASE REPORT: A 3 years old girl was brought by her parents to the DVL OP with the complaints of painful fissures and diffuse thickening of palms and soles since 10 months of her age.

She was normal at birth except for presence of woolly hair, thickening of palms and soles started at 10 months of age, which was progressive and lead to formation of fissures

No history of Consanguity among the parents. No history suggestive of Cardio Vascular System involvement.

On Examination: Woolly hair was present (Figure 1). Non transgradient Hyperkeratosis of palms and soles was seen associated with fissuring (Figure 2-3). Keratosis pilarisis like lesions over extremities (Figure 4). Nails were dystrophic.(Figure 5) Teeth was normal. Conjuctival, Oral and genital mucosa was normal.

\section{INVESTIGATIONS:}

CBP, ESR, RFT, LFT, Sr. Electrolytes, CUE were with in normal limits.

Chest X-ray - normal cardiac and pleuro-pulmonary fields.

ECG -Normal; ECHO -Mild left cardiomyopathy.

Blood samples of parents and patient were sent for the purpose of genetic assessments, reports awaited.

Parents refused biopsy.

As patient ECG didn't show any Arrhythmias, She was not put on any anti arrhythmic medication. Patient was put on symptomatic treatment with emollients and keratolytics. Advised to have regular follow up at Cardiology OP Parents were advised to undergo Genetic Counselling before future pregnancy. 
DISCUSSION: Genodermatoses are inherited genetic skin conditions often grouped into three categories: chromosomal, single gene, and polygenetic. One such example for Genodermatoses is Palmoplantar keratodermas which are a heterogeneous group of disorders characterized by abnormal thickening of the palms and soles. Autosomal recessive and dominant, X-linked, and acquired forms have all been described.

Carvajal syndrome is an example for palmoplantar keratoderma.

Carvajal syndrome is a rare cardiocutaneous syndrome with a triad of wolly hair, striate palmoplantar keratoderma and left ventricular cardiomyopathy.(2)

It is considered as a variant of Naxos disease with predominantly left ventricular involvement, early morbidity and clinical overlapping with dilated cardiomyopathy which has been described by Carvajal-Huerta et al. from Ecuador.(3)

Naxos disease is a rare genodermatosis with woolly hair, keratoderma of palms and soles and cardiomyopathy.(2) It differs from Carvajal syndrome as it presents with diffuse transgradiens palmoplantar keratoderma and right cardiac abnormalities.

In the Carvajal disease variety two different mutations of the desmoplakin gene (Dsp7901del1G and DspG2375R), affecting the C-terminal of the protein, have been found as causative genes. $(4)$

Defects in the linking sites of these proteins can interrupt the contiguous chain of cell adhesion, particularly under conditions of increased mechanical stress or stretch, leading to cell death, progressive loss of myocardium and fibro-fatty replacement.(5)

It is a progressive heart disease and may cause sudden death in a child with early age. Presence of syncopal attacks or left ventricular involvement were risk factors for sudden cardiac deaths.(6)

Whenever a child presents with such a dermatological manifestation, the paediatric cardiologist's consultation must be done at earliest possible. The primary goal of the management is to prevent sudden cardiac death. Implantation of automatic cardioverter defibrillator, antiarrhythmic drugs and management of heart failure are the recommended treatment modalities. ${ }^{(7)}$

The population at risk should be genetically screened. And Parents with a child suffering with Carvajal Syndrome should have genetic counselling before any future pregnancy.

Though there is no specific treatment for Carvajal syndrome, symptomatic treatment for painful fissures should be given.

Till now, no case was reported in Osmania General Hospital.

Whenever a child presents with woolly hair associated with any kind of palmoplantar keratoderma, a search for possible cardiac abnormalities is recommended.(8)

\section{REFERENCES:}

1. Magnetic Resonance Imaging Characteristics in Carvajal Syndrome (Variant of Naxos Disease) 2007 Maria Prompona, MD; Rainer Kozlik-Feldmann, MD; Josef Mueller-Hoecker, MD; Maximilian Reiser, MD; Armin Huber, MD.

2. Naxos disease: a rare occurrence of cardiomyopathy with woolly hair and palmoplantar keratoderma. Rai R1, Ramachandran B, Sundaram VS, Rajendren G, Srinivas CR, Indian J Dermatol Venereol Leprol. 2008 Jan-Feb; 74(1): 50-2.

3. Kaplan SR1, Gard JJ, Carvajal-Huerta L, Ruiz-Cabezas JC, Thiene G, Saffitz JE - Structural and molecular pathology of the heart in Carvajal syndrome 2004 Jan-Feb. 


\section{CASE REPORT}

4. Norgett EE, Hatsell SJ, Carvajal-Huerta L, Cabezas JC, Common J, Purkis PE, et al. Recessive mutation in desmoplakin disrupts desmoplakin-intermediate filament interactions and causes dilated cardiomyopathy, woolly hair and keratoderma. Hum Molec Genet 2000; 9: 2761-6.

5. Tosti, A, Misciali C, Piraccini BA, Fanti PA, Barbareschi M, Ferretti RM. Woolly hair, palmoplantar keratoderma and cardiac abnormalities: Report of a family. Arch Dermatol 1994; 130 522-4.

6. Protonotarios N, Tsatsopoulou A, Patsourakos P, Alexopoulos D, Gezerlis P, Simitsis S, et al. Cardiac abnormalities in familial palmoplantar keratosis. Br Heart J 1986; 56: 321-6.

7. Gatzoulis K, Protonotarios N, Anastasakis A, Tsatsopoulou A, Vlasseros J, Gialafos J, et al. Implantable defibrillator therapy in Naxos disease. Pacing Clin Electrophysiol 2000; 23: 1176-8.

8. Rao BH, Reddy IS, Chandra KS. Familial occurrence of a rare combination of dilated cardiomyopathy with palmo plantar keratoderma and curly hair. Indian Heart J 1996; 48: 161-2

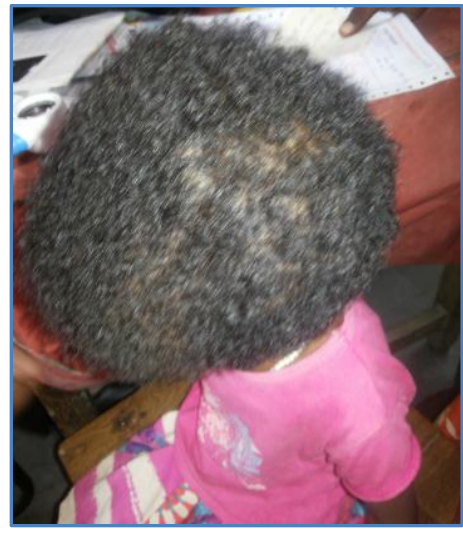

Fig. 1: Wooly Hair

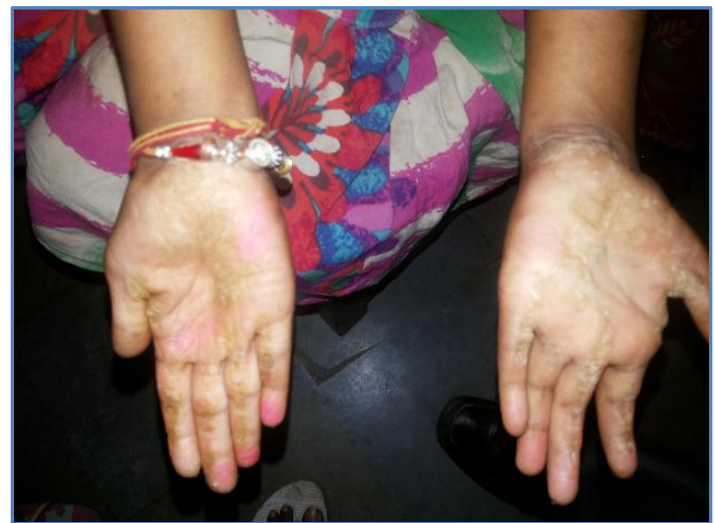

Fig. 2: Hyperkeratosis of Palms

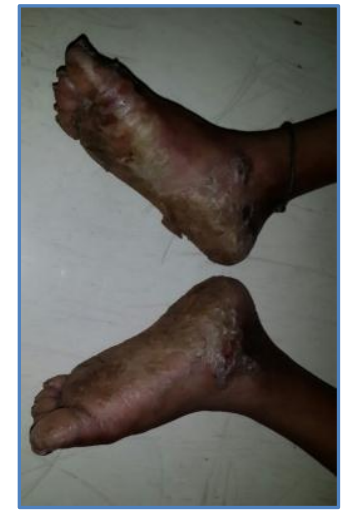

Fig. 3: hyperkeratosis of soles

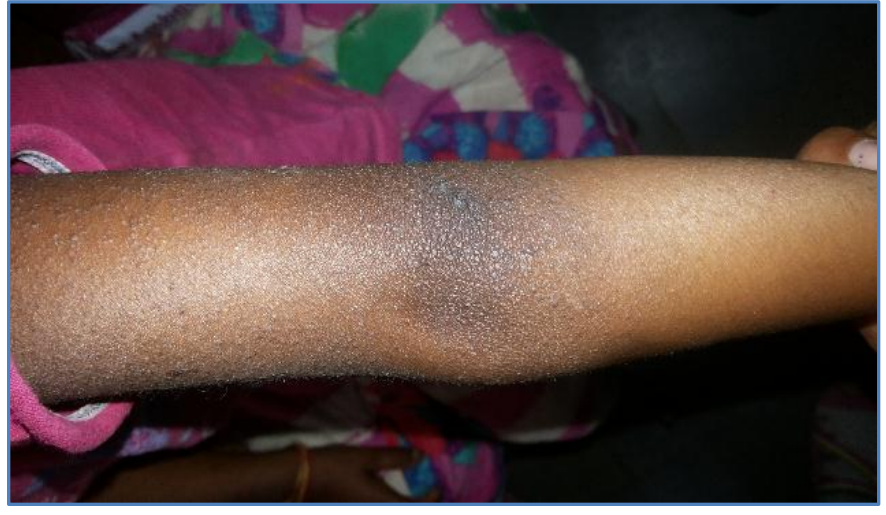

Fig. 4: Keratosis Pilaris Like Lesions Over Extremeties 


\section{CASE REPORT}

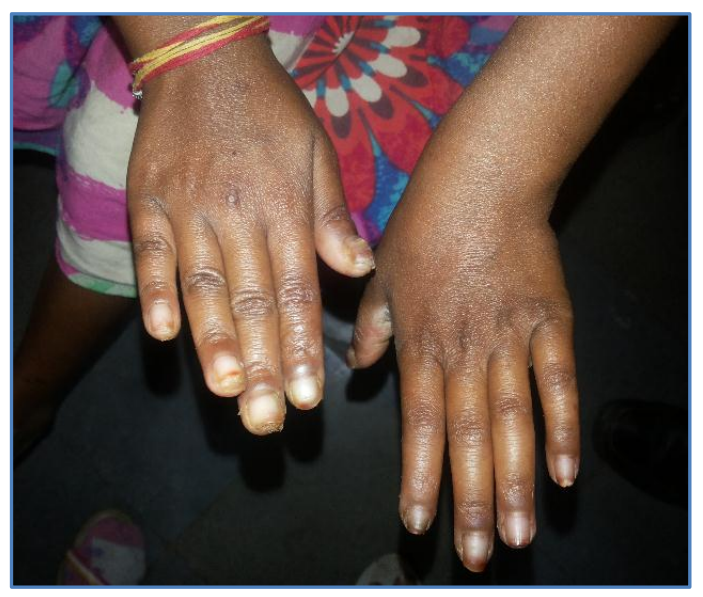

Fig. 5: Dystrophic Nails

\section{AUTHORS:}

1. A. Venkata Krishna

2. Aruna Samarth

3. G. Manmohan

4. Aradya B.

\section{PARTICULARS OF CONTRIBUTORS:}

1. Associate Professor, Department of Dermatology, DVL, Osmania Medical College, Hyderabad Telangana.

2. Assistant Professor, Department of Dermatology, DVL, Osmania Medical College, Hyderabad Telangana.

3. Professor and HOD, Department of Dermatology, DVL, Osmania Medical College, Hyderabad Telangana.

\section{FINANCIAL OR OTHER} COMPETING INTERESTS: None
4. Final Year Post Graduate, Department of DVL, Osmania Medical College, Hyderabad, Telangana.

\section{NAME ADDRESS EMAIL ID OF THE CORRESPONDING AUTHOR:}

Dr. Aruna Samarth,

H. No-2-1-147,

Nallakunta, Hyderabad-500044,

Telangana.

E-mail: drarunasamarth.derma@gmail.com

Date of Submission: 22/07/2015.

Date of Peer Review: 23/07/2015.

Date of Acceptance: 13/08/2015.

Date of Publishing: 20/08/2015. 